\title{
latrogenic Injury to the Posterolateral Knee during Anterior Cruciate Ligament Reconstruction with Anteromedial Portal Technique
}

\author{
Sholahuddin Rhatomy ${ }^{1,2 *}$, Fajar Mahda ${ }^{3}$, Riky Setyawan ${ }^{3}$, Thomas Edison Prasetyo ${ }^{3}$, Nicolaas C. Budhiparama ${ }^{4}$ \\ ${ }^{1}$ Department of Orthopaedics and Traumatology, Dr. Soeradji Tirtonegoro General Hospital, Klaten, Indonesia; ${ }^{2}$ Faculty of \\ Medicine, Public Health, and Nursing, Universitas Gadjah Mada, Yogyakarta, Indonesia; ${ }^{3}$ Soeradji Tirtonegoro Sport Center and \\ Research Unit, Dr. Soeradji Tirtonegoro General Hospital, Klaten, Indonesia; ${ }^{4}$ Nicolaas Institute of Constructive Orthopaedics \\ Research and Education Foundation for Arthroplasty and Sports Medicine, Medistra Hospital, Jakarta, Indonesia
}

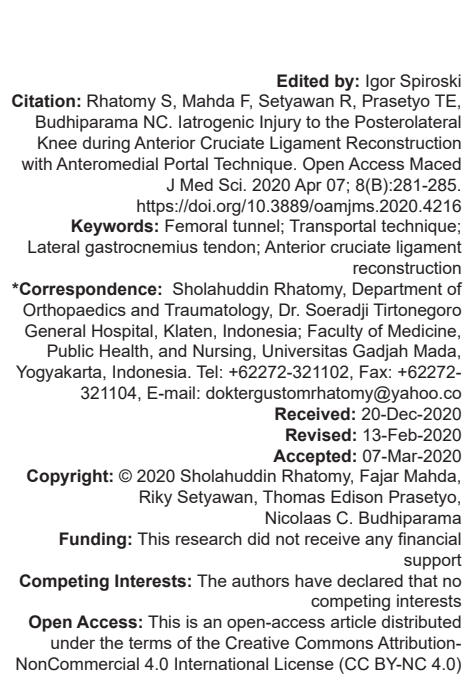

\section{Abstract}

BACKGROUND: Femoral tunnel reaming through anteromedial portal, also known as transportal technique, allows for anatomic femoral tunnel placement in restoring anterior cruciate ligament (ACL) kinematics. This procedure may cause iatrogenic injury to the posterolateral structures of the knee.

PURPOSE: This study aims to assess the risk of posterolateral structure injury in ACL reconstruction using transportal technique.

METHODS: ACL reconstruction using transportal technique was performed in 20 patients. Clinical and radiological examination was performed preoperatively and 1 month postoperatively. Clinical examination included any pain or paresthesia on posterolateral area of the knee, varus alignment of the knee, abnormal gait, and specific tests for posterolateral stability. Radiological evaluation was plain radiography and stress radiography for posterolateral stability, and magnetic resonance imaging (MRI) for assessing structural damage.

RESULTS: Post-operative evaluation showed pain in posterolateral area in five patients, numbness on posterolatera knee in one patient, both pain and numbness in two patients and lateral gastrocnemius muscle injury on MRI in six patients. We did not find varus knee alignment and abnormal gait. Specific tests were negative in post-operative evaluation. Post-operative radiographic imaging did not show the sign of lateral widening.

CONCLUSION: Femoral tunnel drilling using transportal technique in ACL reconstruction is safe even it might risk to damage lateral gastrocnemius muscle, according to clinical and MRI findings.

\section{Introduction}

The main function of the anterior cruciate ligament $(A C L)$ is resisting anterior tibial translation and maintaining rotational stability [1], [2]. The importance of $A C L$ in rotational stability of the knee is to resist tibial rotation in internal direction and valgus torsion. Technique for $A C L$ reconstruction has changed according to these new findings [3]. Recent anatomical and biomechanical studies have suggested that improvement of graft placement (e.g., lowering the femoral tunnel from 11 to 10 o'clock position) provided better control in rotational instability [4], [5].

Two common techniques for creating femoral tunnel are transtibial technique and anteromedial portal (transportal) technique. In transtibial technique, femoral tunnel is approached through the tibial tunnel, whereas in transportal technique, femoral tunnel is made using an additional arthroscopy portal in anteromedial area [5]. Anatomic femoral tunnel placement with transtibial technique is difficult to perform. The risks might be avoided with an additional small incision on anteromedial area as an entry point for drills. This transportal technique allows more anatomic placement of femoral tunnel [4], [5].

Injury to posterolateral structures may increase knee instability and disturb knee kinematics. There were few studies regarding an iatrogenic injury affect to the patients and to the knee stability, especially with the developed transportal technique. This study aims to investigate soft-tissue injuries clinically and radiologically in posterolateral knee during $A C L$ reconstruction using transportal technique.

\section{Methods}

\section{Study design}

This study was a cohort prospective study that was investigating soft-tissue injuries in posterolateral 
area of knee when performing $A C L$ reconstruction surgery with transportal technique. All included patients examined clinically and radiologically at 1 month after surgery. The study was conducted in Soeradji Tirtonegoro General Hospital Klaten, Indonesia. This study was approved by Medical Ethics Committee with IRB number KE/FK/0248/EC/2019. Between November 2018 and January 2019, patients with chronic total ACL rupture were recruited consecutively in the outpatient clinic in Soeradji Tirtonegoro General Hospital Klaten, Indonesia by one orthopedic surgeon (S.R.). After assessing subjects eligibility, they were then included in this study. Eligibility criteria are shown in Table 1.

\section{Assessing ACL injury}

One orthopedic surgeon (S.R.) performed history taking and clinical evaluation to all patients with chief complaint of chronic knee instability. History of trauma to

Table 1: Eligibility criteria

\begin{tabular}{|c|c|}
\hline Inclusion criteria & Exclusion criteria \\
\hline \multicolumn{2}{|l|}{ Patients with $A C L$ rupture } \\
\hline 1. Chronic total ACL rupture (>1 month) & 1. Presence of soft-tissue injury other than $\mathrm{ACL}$ \\
\hline 2. In unilateral knee & $\begin{array}{l}\text { 2. Presence of any fractures including avulsion } \\
\text { fracture }\end{array}$ \\
\hline 3. Age $18-50$ years & 3. Bilateral ACL injury \\
\hline $\begin{array}{l}\text { 4. Confirmed by clinical examination, } \\
\text { MRI, and knee arthroscopy }\end{array}$ & 4. Previous invasive procedures to knee joint \\
\hline
\end{tabular}

the knee, onset of the complaints, knee pain, and feeling of joint locking were taken from the patients. Pre-operative pain, paresthesia, or numbness in posterolateral area of the knee were also noted. Special test of the knee included anterior drawer test, posterior drawer test, McMurray test, dial test, external rotation recurvatum test, posterolateral drawer test, posterolateral external rotation test, revers pivot shift test, and varus stress test. These specific tests were used to assess injury to multiligamentous structures of the knee [6].

If $\mathrm{ACL}$ injury was suspected, standing knee X-ray, knee stressed radiography, and knee magnetic resonance imaging (MRI) were obtained. $X$-ray examination was done in standing position with anteroposterior and lateral view of the knee. X-ray was used to evaluate for fracture or bony avulsion, malalignment of the knee joint mechanical axis. Stressed test radiography was done to check the medial or lateral knee stability. MRI was used to locate damage of ligament, tendon, meniscus, and cartilage. Knee arthroscopy was used as the gold standard of diagnosing injury of knee intra-articular structures. ACL reconstruction was performed following a confirmed ACL rupture.

\section{ACL Reconstruction}

Patients that were fulfilled the inclusion criteria will be treated with $\mathrm{ACL}$ reconstruction.
After confirming the ACL rupture, then the graft was harvested from the ipsilateral peroneus longus tendon. First, the skin was incised approximately $2.5 \mathrm{~cm}$ above and $1 \mathrm{~cm}$ behind lateral malleolus. The tendon of peroneus longus and peroneus brevis was identified. An end-to-side suture was made from the distal area of peroneus longus tendon to the peroneus brevis tendon. Tendon stripper was used to harvest the peroneus longus tendon around $4 \mathrm{~cm}$ below the head of fibula.

Further debridement was carried out inside the knee joint to improve visualization. A $2 \mathrm{~mm}$ guide wire was inserted to the femoral footprint using transportal technique. K-wire was inserted through posterolateral side of the knee with the knee in full flexion position. Initial reaming was performed using a $5-\mathrm{mm}$ drill through outer side of the femoral cortex (Figure 1). Second reaming was performed according to the graft diameter. For tibial tunnel placement, guiding wire was

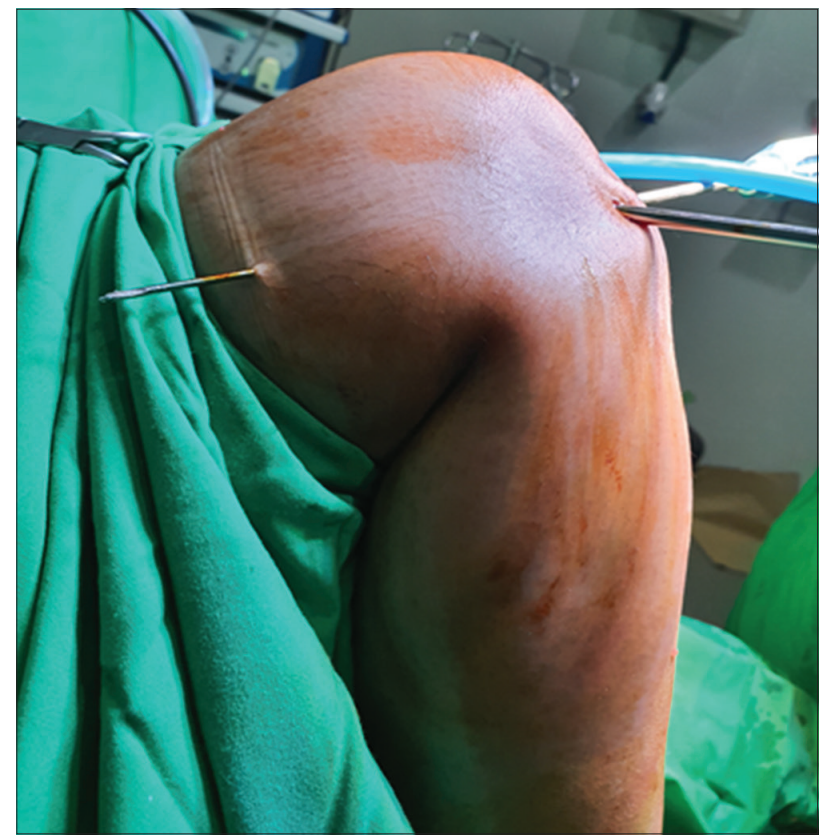

Figure 1: Initial reaming through outer side of femoral cortex

inserted at the center of ACL tibial footprint. By lowspeed drilling technique, the tibial tunnel was created with suitable size in accordance to the graft diameter.

The prepared graft was passed through the canal from the tibia to the femur, and fixated to the femur using an adjustable loop suspensory device (GraftMax ${ }^{\circledR}$, Conmed $^{\odot}$, USA). Fixation to the tibia was done using a bioabsorbable screw (Bioscrew ${ }^{\circledR}$, Conmed $^{\circledR}$, USA) with the knee which was flexed $30^{\circ}$. Stability of the joint after fixation was assessed by anterior drawer test and was compared to before fixation.

Patients were hospitalized for 1 day. Before discharge, they were referred to rehabilitation department to begin the post-operative rehabilitation program. All patients were prescribed 3 weeks partial weight bearing, followed by full weight bearing. Gradual 
range of motion training for knee flexion and extension was also initiated immediately.

\section{Follow-up}

After 1 month post-reconstruction, patient was scheduled for monitoring and evaluation. Assessment was performed by the same orthopedic surgeon (S.R.). Patients were evaluated about their pain or numbness around the posterolateral of the knee.

We performed some knee physical examination. Patients were asked to walk to assess their gait. Any difference of the gait phases than normal, we recorded it as a positive case. Then, we evaluated varus and valgus test, dial test, external rotation recurvatum test, posterolateral drawer test, posterolateral external rotation test, and revers pivot shift test.

The objective evaluation included lateral widening in knee X-rays (with and without stressed) and presence of structural damage seen in knee MRI. On MRI, we evaluated lateral structures such as gastrocnemius, biceps femoris, popliteus, plantaris, and lateral collateral ligament.

\section{Results}

Between November 2018 and January 2019, there were 47 patients who seek medical care for the first time at outpatient clinic that clinically diagnosed with ACL injury based on their history and physical examination. Twenty-seven patients were excluded from the study, as shown in Figure 2.

The baseline characteristics of the patients included in this study are shown in Table 2 . There were 12 female and 8 male subjects. Their age ranged from

Table 2: Baseline Characteristics

\begin{tabular}{lll}
\hline Characteristics & Mean (SD) & $\mathrm{n}(\%)$ \\
\hline Age & $25.2 \pm 4.7$ & \\
Sex & & $12(60)$ \\
$\quad$ Female & & $8(40)$ \\
$\quad$ Male & $22.8 \pm 3.6$ & \\
BMl & & $18(90)$ \\
Cause of ACL rupture & & $2(10)$ \\
$\quad$ Sports related & \\
$\quad$ Accident &
\end{tabular}

18 to 50 years with a mean age of $25.2 \pm 4.7$ years. Cause of the injury was $18(90 \%)$ in sports related or $2(10 \%)$ in accidental trauma. Mean body mass index was $22.8 \pm 3.6$.

The follow-up details are shown in Table 3. Two patients complained of both pain and numbness in the posterolateral knee, five patients reported pain only and one patient complained numbness only. There was no varus abnormality of the knee while standing and no
47 patients clinically diagnosed with $A C L$ rupture

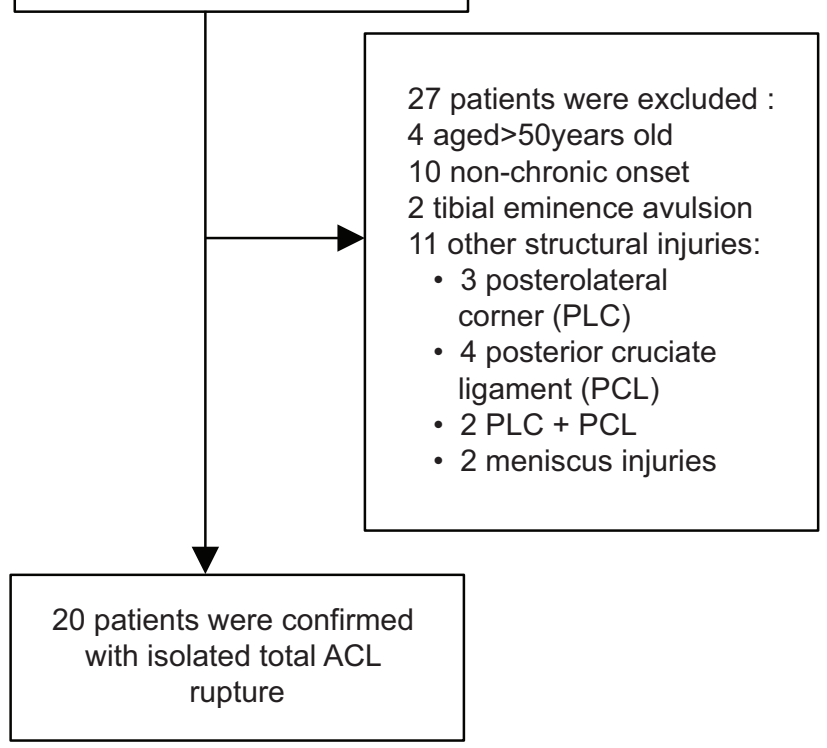

Figure 2: Study flow chart. ACL: Anterior cruciate ligament; MRI: Magnetic resonance imaging

abnormal gait seen at walking. Dial test, external rotation recurvatum test, posterolateral draw test, posterolateral external rotation test, reverse shift pivot test, and varus stress test of all patients were all negative.

Table 3: Follow-up 1 month after ACL reconstruction

\begin{tabular}{ll}
\hline Evaluation & Number of positive cases, $\mathrm{n}(\%)$ \\
\hline Patient's subjective & \\
Pain on posterolateral side & $5(25)$ \\
Numbness on posterolateral side & $1(5)$ \\
Both pain and numbness on posterolateral side & $2(10)$ \\
Physical examination & \\
Varus knee on standing & 0 \\
Gait abnormality & 0 \\
Dial test & 0 \\
External rotation recurvatum test & 0 \\
Posterolateral drawer test & 0 \\
Revers pivot shift test & 0 \\
Varus stress test & 0 \\
Plain X-ray & \\
Abnormal result & 0 \\
Stressed X-ray & \\
Abnormal result & 0 \\
MRI & \\
Injury to lateral gastrocnemius & $6(30)$ \\
Injury to biceps femoris & 0 \\
Injury to popliteus & 0 \\
Injury to plantaris & 0 \\
Injury to other structures (LCL, etc) & 0 \\
\hline ACL: Anterior cruciate ligament, MRI: Magnetic resonance imaging, LCL: Lateral collateral ligament. &
\end{tabular}

The MRI revealed that lateral gastrocnemius tendon was torn $(2-5 \mathrm{~mm})$ at the origin of the muscle in six patients. All these patients had pain or numbness. Plain and stressed X-ray radiography did not show lateral widening

\section{Discussion}

Our primary finding was that some patients experienced pain or numbness $(25 \%$ and $5 \%$, respectively) or both pain and numbness in $10 \%$ 
on the posterolateral area of the knee. Only lateral gastrocnemius lesion was present in MRI. No abnormalities were found in physical examination, suggesting of good stability of posterolateral knee.

In ACL reconstruction, femoral tunneling using transportal technique requires $\mathrm{K}$-wire to penetrate structures at posterolateral side of the knee. The pitfalls were that operator could not determine the exact direction of the exit point of $\mathrm{K}$-wire. This technique increases the risk of posterolateral structures injury of the knee, posterior wall, and femoral condyles damage [7], [8], [9]. Some literatures did not discuss about iatrogenic injury to the posterolateral structures in details [10], [11], [12], [13]. Hall et al. performed a descriptive study on cadavers that they drilled the femoral tunnel from low-medial accessory portal to femoral cortex, with the knee flexed at $120^{\circ}, 90^{\circ}$, and $70^{\circ}$. That procedure may increase the risk of injury at $70^{\circ}$ knee flexion and less with more flexion. Biceps femoris tendon was at risk if guide pins were inserted at $70^{\circ}$, but no injury was found at $120^{\circ}$ [14]. A study by Nakamura et al. [12] found that lower flexion angle might have higher risk of damage to the common peroneal nerve and posterior articular cartilage. This risk was also reduced by increasing the flexion angle. Plantaris muscle was injured in ten knees (50\%), lateral gastrocnemius muscle in 9 (45\%), and biceps femoris muscle in 4 (20\%). Evaluation of the knee MRI in our study found that only lateral gastrocnemius was injured in six knees (30\%).

We did not found any abnormality in physical examination for posterolateral structures. This finding suggested a relatively stable posterolateral corner even with a sustained iatrogenic injury [6], [15]. A primary posterolateral corner disruption may increase the risk of graft failure after ACL reconstruction because of the disturbance to knee biomechanics. It might be suggested that femoral tunnel drilling using transportal technique will result in good posterolateral stability [6], [16].

Wang et al. [17] performed a dynamic postACL reconstruction knee kinematics study while walking, comparing the transportal with transtibial technique. Anterior-posterior translation during swing phase and femoral external rotation at midstance was better restored in transportal than in transtibial technique. Another kinematics study by Schairer et al. [18] yielded similar outcomes in favor of transportal technique. Translation and rotation of the tibia and the tibiofemoral contact area was measured. They found that transportal technique resulted in comparable measurement to the healthy contralateral knee. This kinematics improvement might be explained with better joint stability in transportal technique. In our study, we found that there was no gait abnormality at 1 month after $A C L$ reconstruction using transportal technique.

Our study has several limitations. First, this study has no comparison group. Second, time to follow-up was relatively short. Therefore, further research is needed to consider the best angle of the knee flexion to minimalize damage to soft tissues in posterolateral area.

\section{Conclusion}

Femoral tunnel drilling using transportal technique in ACL reconstruction is safe even it might risk to damage lateral gastrocnemius muscle according to clinical and MRI findings. The injury of the gastrocnemius can be reduced using the smallest pin during femoral tunnel drilling.

\section{References}

1. Morgan JA, Dahm D, Levy B, Stuart MJ. Femoral tunne malposition in $A C L$ revision reconstruction. J Knee Surg. 2013;25(5):361-8.

PMid:23150344

2. Ahn JH, Jeong HJ, Ko CS, Ko TS, Kim JH. Three-dimensiona reconstruction computed tomography evaluation of tunne location during single-bundle anterior cruciate ligament reconstruction: A comparison of transtibial and 2-incision tibial tunnel-independent techniques. Clin Orthop Surg. 2013;5(1):2635. https://doi.org/10.4055/cios.2013.5.1.26

PMid:23467279

3. Herbort M, Domnick C, Raschke MJ, Lenschow S, Förster T, Petersen W, et al. Comparison of knee kinematics after single-bundle anterior cruciate ligament reconstruction via the medial portal technique with a central femoral tunnel and an eccentric femoral tunnel and after anatomic double-bundle reconstruction. Am J Sports Med. 2016;44(1):126-32. https:// doi.org/10.1177/0363546515611646

PMid:26574601

4. Kopf S, Pombo MW, Shen W, Irrgang JJ, Fu FH. The ability of 3 different approaches to restore the anatomic anteromedial bundle femoral insertion site during anatomic anterior cruciate ligament reconstruction. Arthroscopy. 2011;27(2):200-6. https:// doi.org/10.1016/j.arthro.2010.07.010

PMid:20970948

5. Tashiro $\mathrm{Y}$, Okazaki K, Uemura M, Osaki K, Matsubara H, Toyoda $\mathrm{K}$, et al. Comparison of transtibial and transportal techniques in drilling femoral tunnels during anterior cruciate ligament reconstruction using 3D-CAD models. Open Access J Sport Med. 2014;5:65-72. https://doi.org/10.2147/oajsm.s59297 PMid:24744615

6. Kennedy NI, LaPrade CM, LaPrade RF. Surgical management and treatment of the anterior cruciate ligament/posterolateral corner injured knee. Clin Sports Med. 2017;36(1):105-17. https://doi.org/10.1016/j.csm.2016.08.011

PMid:27871653

7. Lee DH, Kim HJ, Ahn HS, Bin SI. Comparison of femoral tunnel length and obliquity between transtibial, anteromedial portal, and outside-in surgical techniques in single-bundle anterior cruciate ligament reconstruction: A meta-analysis. Arthroscopy. 
2016;32(1):142-50. https://doi.org/10.1016/j.arthro.2015.07.026 PMid:26422705

8. Osti M, Krawinkel A, Ostermann M, Hoffelner T, Benedetto KP. Femoral and tibial graft tunnel parameters after transtibial, anteromedial portal, and outside-in single-bundle anterior cruciate ligament reconstruction. Am J Sports Med. 2015;43(9):2250-8. https://doi.org/10.1177/0363546515590221 PMid:26138734

9. Hofbauer M, Muller B, Murawski CD, van Eck CF, Fu FH. The concept of individualized anatomic anterior cruciate ligament (ACL) reconstruction. Knee Surg Sport Traumatol Arthrosc. 2014;22(5):979-86. https://doi.org/10.1007/s00167-013-2562-4 PMid:23740328

10. Bombaci $\mathrm{H}$, Aykanat $\mathrm{F}$. Drilling through anteromedial portal with a femoral aiming device ensures a sufficient length and a proper graft position, and prevents posterior wall breakage during anterior cruciate ligament reconstruction. Eur J Orthop Surg Traumatol. 2018;28(7):1403-9. https://doi.org/10.1007/ s00590-018-2211-1

PMid:29705911

11. Robin BN, Jani SS, Marvil SC, Reid JB, Schillhammer CK, Lubowitz $\mathrm{JH}$. Advantages and disadvantages of transtibial, anteromedial portal, and outside-in femoral tunnel drilling in single-bundle anterior cruciate ligament reconstruction: A systematic review. Arthroscopy. 2015;31(7):1412-7. https:// doi.org/10.1016/j.arthro.2015.01.018

PMid:25749530

12. Nakamura M, Deie M, Shibuya H, Nakamae A, Adachi $N$, Aoyama $\mathrm{H}$, et al. Potential risks of femoral tunnel drilling through the far anteromedial portal: A cadaveric study. Arthroscopy. 2009;25(5):481-7. https://doi.org/10.1016/j.arthro.2008.11.010 PMid:19409305

13. Bonner KF, Mannino A. An alternative technique to avoid injury to the medial femoral condyle when reaming the femoral tunnel during anterior cruciate ligament reconstruction. Arthrosc Tech. 2017;6(1):e149-55. https://doi.org/10.1016/j.eats.2016.09.017 PMid:28373954

14. Hall MP, Ryzewicz M, Walsh PJ, Sherman OH. Risk of iatrogenic injury to the peroneal nerve during posterolateral femoral tunnel placement in double-bundle anterior cruciate ligament reconstruction. Am J Sports Med. 2009;37(1):109-13. https:// doi.org/10.1177/0363546508324177

PMid:18952904

15. LaPrade RF, Resig S, Wentorf F, Lewis JL. The effects of grade III posterolateral knee complex injuries on anterior cruciate ligament graft force. A biomechanical analysis. Am J Sports Med. 1999;27(4):469-75. https://doi.org/10.1177/036354 65990270041101

PMid: 10424217

16. LaPrade RF, Heikes C, Bakker AJ, Jakobsen RB. The reproducibility and repeatability of varus stress radiographs in the assessment of isolated fibular collateral ligament and grade-III posterolateral knee injuries. An in vitro biomechanical study. J Bone Joint Surg Am. 2008;90(10):2069-76. https://doi. org/10.2106/jbjs.g.00979

PMid: 18829903

17. Wang H, Fleischli JE, Zheng N. Transtibial versus anteromedial portal technique in single-bundle anterior cruciate ligament reconstruction: Outcomes of knee joint kinematics during walking. Am J Sports Med. 2013;41(8):1847-56. https://doi. org/10.1177/0363546513490663

PMid:23752955

18. Schairer WW, Haughom BD, Morse LJ, Li X, Ma CB. Magnetic resonance imaging evaluation of knee kinematics after anterior cruciate ligament reconstruction with anteromedial and transtibial femoral tunnel drilling techniques. Arthroscopy. 2011;27(12):166370. https://doi.org/10.1016/j.arthro.2011.06.032

PMid:21958672 